\title{
PASSAGE TO MODERNITY: LEAVES OF GRASS AND THE 1853 CRYSTAL PALACE EXHIBITION IN NEWYORK
}

\author{
Ed Cutler
}

As HERALD TO A NEW ERA HIMSELF, Walt Whitman's admiration for the grand industrial exhibitions of the nineteenth century is not surprising, even if the poetry he wrote to honor these events may surprise a contemporary reader. The invocation of the Muse in "Song of the Exposition," for instance, was commissioned by the Fortieth National Exposition of the American Institute in 1871:

By thud of machinery and shrill steam-whistle undismay'd, Bluff'd not a bit by drain-pipe, gasometers, artificial fertilizers, Smiling and pleas'd with palpable intent to stay, She's here, install'd amid the kitchen ware! ${ }^{1}$

While such verse might fail to persuade that the Muse has in fact migrated from Greece to the New World, readers of Whitman may not recognize the extent to which exhibitions, the industrial exhibition at the New York Crystal Palace in 1853 in particular, served to model the very social prospects and challenges of modernity against which his most innovative and celebrated poetry took form-particularly the centerpiece of every edition of Leaves of Grass, "Song of Myself." The plan of Whitman's first book was in fact to "make an exhibition," according to Emory Holloway. ${ }^{2}$ Following the format of a nineteenth-century "world exhibition," Whitman's poetic analogue was to become "a repository of all the heterogenous displays his age and land afforded him." Although the resulting first edition of Leaves of Grass is not overtly cast as an exhibition, its heterogeneous catalogues draw upon a technique of presentation common to the exhibition gallery, and many poems directly trope upon the discourse surrounding the 1853 exhibition. Whitman's personal and editorial writings about the Crystal Palace indicate that he discovered there a resonant foreshadowing of global industrial democracy as he would later celebrate it in his 1855 poems. At the exhibition, machinery and sculpture, the products of the laborer and the artist, occupied common, public space for the supposed education and improvement of America's laboring classes. Radical integration of dispar- 
ate discursive registers and multiform catalogues of social and historical phenomena are hallmark features of the 1855 Leaves of Grass, and this essay will demonstrate that the Crystal Palace uniquely stood as the apotheosis of the representational strategies and political motives that would come to distinguish Whitman's early verse, as revealed in the contemporaneous writings of Whitman and other commentators on the exhibition.

Although scholarship on Whitman has regularly turned to nineteenth-century material and print culture to shed light upon the discursive contexts for the first and subsequent editions of Leaves of Grass, the event of the Crystal Palace exhibition has to this point received only passing consideration as a potential model of inspiration, which is somewhat surprising given Whitman's recollection that he attended the event "days and nights" for nearly a year during the formative phase of his writing the first edition $(P W 681) .^{3}$ In asserting the source-significance of the 1853 exhibition on the 1855 Leaves of Grass, however, I wish to stress from the outset that it appeared to Whitman as much more than simply a formal model for the heterogeneous displays of the modern age that would reappear in the first edition. The exhibition was, after all, a deeply rhetorical project in its own right, one that sought to rationalize nineteenth-century modernity and to portray favorably the sweeping social transformations brought about by an emerging international industrial capitalism. The varied discursive elements and conceptual meditations associated with Whitman's early verse-namely, celebration of the American laborer, the radical fusion of disparate historical, cultural and regional forms, the self-conscious marking of its own modernitywere features of the Crystal Palace exhibition itself. And because the attempt to enclose and give optimistic account to the increasingly profuse and spectacular historical present unites the representational goals of both projects, tracing out the relationship between the two sheds light upon the tenuous rhetorical and political motives of Leaves of Grass.

Progressive belief in the power of mass visual display for the improvement of America's laboring classes, along with a metaphysics of historical development and the relation of self to other and self to world, combine in Whitman's new poetics to create a discursive parallel to the ideals and representational strategies of the world exhibition. Yet Whitman's enthusiasm is checked by an undercurrent ambivalence toward the portentous spectacle of modernity the Crystal Palace ushered into mid-nineteenth-century New York. Ultimately, Leaves of Grass reads as a hopeful but wary response to modernity as displayed at the world exhibition, a response that attempts to salvage spiritual perspective in the face of mere spectacle and growing materialism, along with essential, individual identity in an era of accelerating temporal change and social dissolution. 


\section{I \\ Crystal Palaces: London (1851) and New York (1853)}

Proliferating technologies and industrial arts at mid-nineteenth century provided the impetus for the creation of the first "World Exhibition" in London. Joseph Paxton's Crystal Palace was itself the most impressive and "modern" display. The enormous iron and glass enclosure, located in Hyde Park, housed the famous 1851 exhibition. The glass construction improved visibility under its one-hundred-twelve-foot roof, which illuminated a display of industrial products, ornamental gardens, statues and pump-driven fountains. ${ }^{4}$ Thousands of spectators poured through the building, treated to a first-hand view of the products of modern commerce and technology. Viewers took in daguerreotype images of famous people and sights, entertainments such as the phantasmagoria and magic lantern shows, and massive dioramas of classical and modern scenes. For the spectator, writes Susan Buck-Morss, the London Crystal Palace "blended together old nature and new nature-palms as well as pumps and pistons - in a fantasy world that entered the imagination of an entire generation of Europeans." 5

Enchantment with the London exhibition extended beyond Europe. While attending the event, a group of prominent American visitors struck up a plan to replicate it as quickly as possible in New York City. Among them was Horace Greeley, influential editor of the New York Tribune, who saw in the exhibition a chance for the United States to come of age internationally. Embarrassed by weak participation from the United States and encouraged by the overwhelming popular success of the London exhibition, Greeley, along with millionaire A.T. Stewart, James Gordon Bennett and others formed a corporation and secured investment capital to attempt privately what Britain had done only with the financial backing of the empire. A mere two years after the first international exposition, in the summer of 1853, a second Crystal Palace exhibition opened near what is now Bryant Park in New York. Newly elected U.S. President Franklin Pierce and dignitaries of descending rank delivered speeches at the opening before ten-thousand select guests, each of whom declared the event emblematic of the new age of prosperity and increasing world significance for the Republic. Patterned closely after its predecessor, the "Exposition of the Art and Industry of All Nations," as the event was officially titled, housed exhibits within a five-acre iron and glass building similar to the London palace but domed and partitioned like a Greek cross. Although slightly smaller than its London counterpart, the New York version of the Crystal Palace compensated for its diminished overall proportions by boasting the "tallest dome" in the Western world. ${ }^{6}$ Among items displayed were numerous sculptures, paintings, and daguerreotypes, stereoscopes, fountains, a 


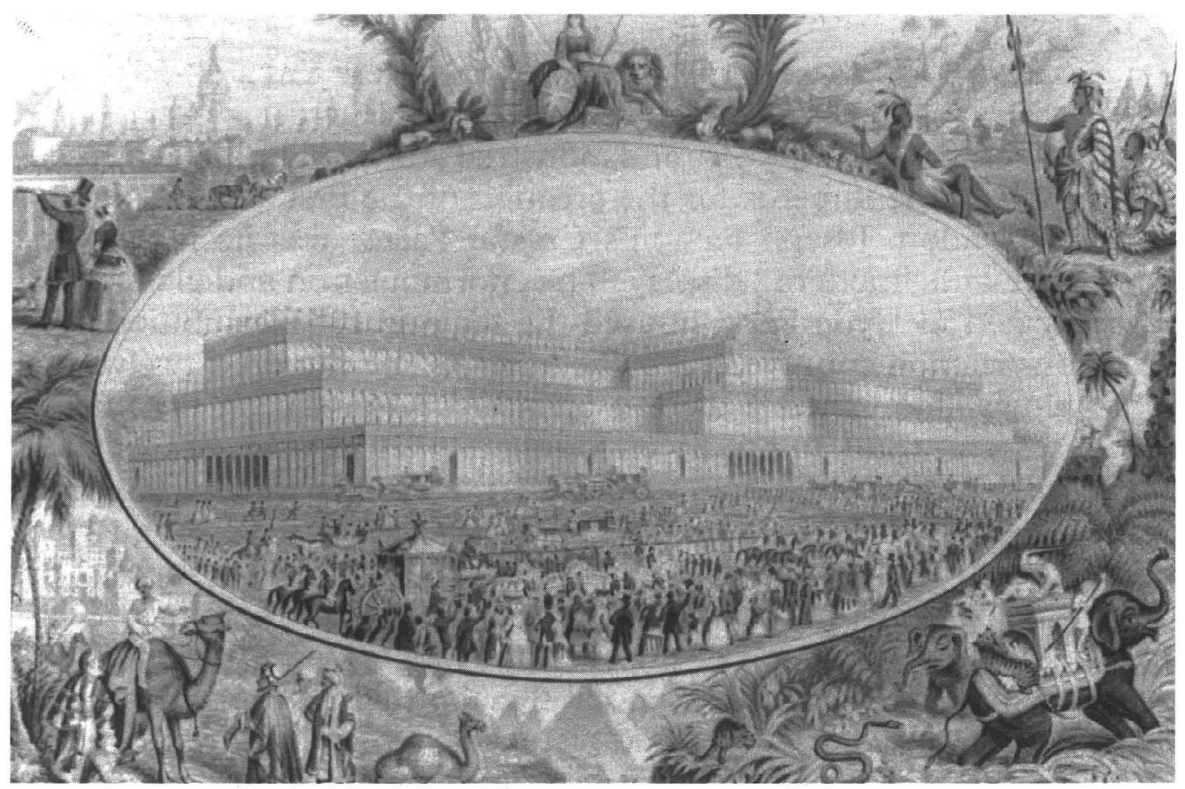

Figure 2. "Metonymic Depiction of the 1851 Exhibition." Courtesy of Brigham Young University Library Special Collections, Artist and Publisher Unknown.

miniature scale model of New York City, a polar bear and other stuffed animals from the Western frontier, gold bars from California, and an array of manufacturing and agricultural equipment (see Figure 1).

The world exhibition in New York staked a claim for international validation at a time when industrialization and urbanization were rapidly transforming the Northeastern United States. The remarkable scale of the exhibit, unprecedented in the United States and in continental Europe (the first of the many Paris exhibitions did not open until 1855), announced the emergent condition of modernity in spectacular fashion. As the goal of the New York exhibition, like that of its London predecessor, was to form a public exhibition of the products of the art and industry of all nations, the massive scope of the enterprise was certainly unmatched; "the art and industry of all nations," after all, conceivably amounts to the totality of world cultural production. To create a sense of global totality in the visual display, the exhibit "represented" the art and industry of the nations by means of a strategic metonymy, a representational device in which selected objects and images, gathered together into a common viewing space, are understood not simply as isolated objects, but as contiguous parts of the totality of historical and cultural "development." Metonymic presentation thus attains to a sense of "the world" in a kind of shorthand-the objects contributed by vari- 
ous nations, representing different cultural-historical stages of scientific and aesthetic development, combined within the ultra-modern Crystal Palaces of London and New York to offer spectators a sort of temporal "cosmorama," providing an experience of the world and its developmental trajectory within the space of a singular and thoroughly modern enclosure. This particular visual encounter with modernity marks the organizing logic behind the grand nineteenth-century exhibitions. Elaborate representations of world cultural history and the diversity of production were metonymically "captured" at the Crystal Palaces, projecting a culminating sense of the temporal present as the embodiment of history and global circumference. In this sense, the early Crystal Palaces marked the viewer's perspective as the very locus of modernity itself (see Figure 2). ${ }^{7}$

Industrial exhibitions relied upon the power of spectacle, and this quality of the massive nineteenth-century industrial exhibitions has generated some influential critical analysis. Walter Benjamin locates the ur-motive of class alienation and mass consumer capitalism in the spectacular nineteenth-century exhibitions, asserting that world exhibitions manufactured for public consumption a dream world of fantasy and desire which turned mere objects into commodity fetishes as they "open[ed] up a phantasmagoria that people enter to be amused." 8 This "enthronement of merchandise, with the aura of amusement surrounding it," according to Benjamin, conditioned people to "submit to being manipulated while enjoying their alienation from themselves and others." The exhibitions thus functioned, in his view, to estrange producers from the products of their own labor, as those products reappeared within a fantastic spectacle-show that converted them into commodity fetishes. Following up on this reading of viewer reception, Rachel Bowlby has more recently noted that "the grand buildings of the Universal Expositions bear a striking resemblance to some more everyday 'palaces of consumption"'-namely, the visual aura of department stores and shopping malls. ${ }^{9}$ In an atmosphere of spectacular abundance, the effect of presenting new commodities and disparate objects, estranged from their "natural" context, was disorienting to many viewers, according to this line of critique. And a sense of displacement is reflected in the accounts of many visitors to the Crystal Palaces. Then seventeen-year-old visitor Samuel Clemens, for instance, would later describe the New York Crystal Palace as "a perfect fairy palace-beautiful beyond description." 10

If wonder and exhilaration characterized the reactions of many to the Crystal Palaces, it is important to note that not all nineteenth-century commentators were rhapsodic. Among the skeptical was Fyodor Dostoevsky, whose Notes from Underground (1864) depicts the London palace as the crowning feature of a reductive and blindly empiricist nineteenth-century modernity. His narrator Underground Man declares: 
New economic relations will follow, ready-made and also calculated with mathematical precision, so that all possible questions will disappear in a single instant, since they all have been provided with answers. And then the Crystal Palace will arise. ${ }^{11}$

Speaking here about the path of industrialization Russia had begun to embark upon, Dostoevsky ironically sets the Crystal Palace as the dubious goal of modernization - an eventual "perfection" of calculation, science and engineering that is at the same time a destruction of real humanity. As Marshall Berman notes in his reading of Dostoevsky: "the building's tone is pompous and ponderous; the message it proclaims is not merely historic culmination but cosmic totality and immutability." 12 Faced with the ominous irrefutability of the Palace, Underground Man denounces all naive celebrants of modern times, observing:

You believe in a crystal edifice, eternal and imperishable, an edifice at which one can never stealthily stick out his tongue or make a fist, even in one's pocket. As for me, I am perhaps afraid of this edifice just because it is crystal and forever imperishable, and because it will be impossible even stealthily to stick out a tongue at it. (40)

To understand this fear, one must have a sense of the enormous cultural power to which the Crystal Palace events appeared to lay claim. By virtue of their scale, both the London and New York palaces bore a certain unquestionable witness to the marvels of modern industrial science and engineering. The contents of the exhibition buildings - the global displays of art and industry-irrefutably legitimized the triumph of modern scientific rationalism, global Western expansion and industrialization. Any sentiment or criticism not aligned with "the times" was in a sense trivialized in the face of the massive edifice and its stark evidence of irreversible modern transformation.

Dostoevsky's sentiments toward the London Crystal Palace, sentiments later echoed in Walter Benjamin's critical history of the nineteenth-century exhibitions in London and Paris, were not altogether shared by Walt Whitman as he contemplated its American counterpart in the 1850's. Dostoevsky's critical concerns do, however, indicate the sense of urgency which compelled Whitman to write. If the rapid ascendancy of applied science and industrialization had rendered all conventional philosophical, theological and aesthetic models obsolete, then a new poetics must build itself upon the modern powers and forms themselves. Whitman was very much attuned to this sense of historic culmination when he began writing Leaves of Grass, his response to what he would later term the "challenge" which "modern science and democracy seem'd to be throwing out" ( $P W 715)$. Yet unlike Dostoevsky, Whitman would engage the modernity of the palace head on. Rather than resist or go underground, the preface to the 1855 Leaves of Grass asserts that he who would be the greatest poet must himself be "transfigured" by "the immediate age," by its "merits and demerits" alike. ${ }^{13}$ 


\section{II \\ The Crystal Palace in America: Mass Entertainment or Mass Empowerment?}

Whitman's ideological relationship to the exhibition is complex and not without contradictions. The Whitman writing in the 1840's and 1850 's appears more inclined to embrace the promises of industry and a progressive, spectacular mode of presenting the modern age than does the Whitman of the 1870's and 1880's. To understand his attitude toward industrial modernity one must note that it changes as, in his eyes, American society changes to the one he described in "Democratic Vistas" as having "solely materialistic bearings" ( $P W$ 424). One should also recognize that the exhibit afforded a uniquely democratic opportunity for the education and edification of laborers, in the view of Whitman and other labor-friendly contemporaries. Far from alienating masses of spectators into a private dream world, the exhibition of Whitman's ardent social hopes would offer the nation's laboring classes an unprecedented opportunity to realize the connection between their handiwork and the increasingly integrated world they were servicing. By setting forth products of world art and industry, Whitman believed, the world exhibition celebrated and made visible the many hands that created them.

As early as 1846, Whitman argued in a Brooklyn Eagle editorial that the city government should arrange "free public exhibition of works of art-painting, statuary, etc." 14 In a later 1846 editorial, he wrote that "we wish every mechanic and laboring man and woman in Brooklyn" would have access to "music, mirth, works of art, genial kindness, and so forth," concluding with another call for the democratization of the galleries: "We wish some plan could be formed which would result in the perpetual free exhibition of works of art here, which would be open to all classes" (Rogers and Black 365). The result of such broad social contact with art, he predicted, would be the increased refinement and spiritual awareness of all classes of the nation's citizenry. This ideal of utilizing public space - the art gallery, the museum, or various urban institutes - for uplifting and educational purposes remained for Whitman a vital particular in his vision of a truly democratic nation.

Not surprisingly, Whitman greeted the Crystal Palace Exhibition's arrival in New York with unchecked enthusiasm. After the doors opened in July of 1853, he became a regular visitor. And if Holloway's biography is to be believed, Whitman was so intensely absorbed in the displays that others took special notice of him:

So curious and persistent was he in his study of whatever specially interested him that he excited the attention of the police, who exercised particular surveillance over him. It was beyond the intelligence of a simple policeman to comprehend how a roughly dressed visitor could stand for hours before Thorwaldsen's marbles unless he were premeditat- 
ing a theft. When, sometime later, Walt made the acquaintance of these same policemen, they confided to him, to his amusement, their former fears and precautions. (97)

This anecdote certainly overplays the myth of Walt Whitman as the roughly dressed but intensely thoughtful visitor. And it is doubtful, moreover, that Thorwaldsen's massive marble christus would have been considered vulnerable to theft. But that Whitman did frequent the Crystal Palace and make a copious study its contents is not in dispute, nor a matter of surprise, given his repeated earlier calls for mass public exhibitions of the arts.

The New York exhibition, however, was significant to Whitman for much more than its providing opportunity to view sculpture and painting. The event effectively combined the art gallery, the museum and the institute-indeed all that could be said to represent world-historical experience. In a short series of recollections published as "Memoranda" in Good-Bye My Fancy (1891), which Whitman prefaces as revealing the "autobiographic, and even egotistic" context for his Leaves of Grass, the opening entry-titled "A World's Show"-would remember the Crystal Palace Exhibition as a landmark moment of democratic promise for the laborer:

New York, Great Exposition open'd in 1853.-I went a long time (nearly a year)-days and nights - especially the latter - as it was finely lighted, and had a very large and copious exhibition gallery of paintings (shown best at night, I tho't) - hundreds of pictures from Europe, many masterpieces - all an exhaustless study - and, scatter'd thro' the building, sculptures, single figures or groups - among the rest, Thorwaldsen's "Apostles," colossal in size- and very many fine bronzes, pieces of plate from English silversmiths, and curios from everywhere abroad - with woods from all lands of the earth - all sorts of fabrics and products and handiwork from the workers of all nations. (PW 681)

This recollection of the exhibition contents, the "products and handiwork from the workers of all nations" mingled with traditional arts, indicates something of the democratic vision set forth in Whitman's earlier editorials. Breaking both class and cultural barriers, the Crystal Palace as Whitman remembered it celebrated in a single vast gesture the combined production of fine artists and laborers across both time and space.

Organizers of the New York exhibition had also promoted the event as an unprecedented opportunity for educating the laboring classes in finer points of art and industry. Horace Greeley asserts that the purpose of the event was not to amuse, but rather to educate, America's working classes:

If this work of many hands shall induce, as we trust it may, some thousands of our younger mechanics, artisans and laborers, to regard the mighty Exhibition, not as a vast curiosity-shop or raree-show, nor yet as a mere Arch of Triumph, erected in honor of Labor, but as the grandest and most instructive University ever opened to themselves 
and their children on this continent, or ever but once in the world, then will its end have been accomplished, and our labor abundantly rewarded. (Art and Industry iv)

A similarly egalitarian view of the Crystal Palace appeared in the American Phrenological Fournal earlier in the year, albeit one with less stress on education and more on entertainment:

Here will be collected multitudes of all nations; but the great and crowning feature of the enterprise is, that it will offer amusement and recreation to the working classes, such that they can find no where else; that it will be a Palace For The People. ${ }^{15}$

While somewhat different in outlook (the Phrenological fournal forecasting something closer to Benjamin's view of the fetishistic character of the exhibitions), both statements indicate the prevailing rhetorical tendency to celebrate the event as an opportunity to elevate mass consciousness. Whitman's hopes for class elevation were thus shared by other commentators who also envisioned the exhibition bettering the condition of the working classes, refining their cultural taste and providing instruction in the latest industrial and technological developments. An anonymous letter to the editor in the New York Daily Tribune, for instance, sought to assure readers that the "Bacchanalian circle drawn round the Crystal Palace" (a reference to the grogshops and carnivalesque displays which had sprung up around the building), had not deterred visitors from experiencing the "delicate traces of intellect" and the "intricacies of imagination, invention and enthusiasm" which the exhibition alone can offer. ${ }^{16}$

Beyond the exposure of the masses to high culture, however, the exhibition, in Greeley's view, "had another use-a moral, if not religious use," in that it taught the "wonderful and touching unity [that] pervades the relations of the [human] race" (Art and Industry 51). The products on display, he professed, were palpable signs of this new unity, ushered in by an expanding global economy:

There is hardly an article in the Crystal Palace to which the labor of all the world has not in some sort contributed-hardly a machine which is not an embodied record of the industrial progress of the world-hardly a fabric which, analyzed, does not carry us to the ends of the earth, or which does not connect us intimately with people of every clime - with miners who tortured its raw material from the dark cave, or the diver who brought it from the bottom of the sea-with the solitary mariner who shielded it from the tempests-with the poor, toil worn mechanic who gave it form or color, or with the artist who imparted to it its final finish. (Art and Industry 50-51)

This declaration certainly resonates with the Whitmanian ensemble of laborers who comprise an integrated and abundant American democracy; the rhetoric of Greeley also echoes Whitman's grandest political ideal in the observation that "no man liveth to himself alone, even in his most ordinary occupations; he is part and parcel of us, as we are of him" 
(51). The 1855 preface expresses almost identically, "what answers for me an American must answer for any individual or nation that serves for a part of my materials" (xii). The 1853 exhibition, then, was distinguished in the eyes of some as a singular representation of new democratic possibility, one that articulated universal-historical and economic development by means of an implicit social metonymy which would become the governing ethos of Leaves of Grass two years afterward.

In addition to the ideals of mass education and universal political sociality for the laborer, the Crystal Palace building inspired Whitman as a uniquely modern structure - a concept central to his early poetics. The 1855 preface proclaims that the "direct trial of him who would be the greatest poet is today," and that a poet must "flood himself with the immediate age as with vast oceanic tides" (xi, emphasis mine). The Crystal Palace building itself, he believed, almost singularly embodied this ideal. In an 1857 Brooklyn Daily Eagle article on noteworthy structures in New York, Whitman wrote:

We must not conclude this article without an allusion to the Crystal Palace, an edifice certainly unsurpassed anywhere for beauty and all the other requisites of a perfect edifice. At present, few persons pay any attention to architecture in its higher planes, its philosophy, its reference to all other things. . . . We suppose it must be for that reason that the New York City Crystal Palace is not universally confessed to be what it certainly is - an original, esthetic, perfectly proportioned American edifice-one of the few that put modern times not beneath old times, but on an equality with the best of them. ${ }^{17}$

Whitman's description of the Crystal Palace all but parallels his conception of his poetics; in its ability to forge equivalence between past and present, to reference "all other things," and to serve as an "original," "esthetic," and "American" form, the ultra-modern building appears as the architectural analogue of his poetic ambitions for Leaves of Grass.

The 1853 exhibition at the Crystal Palace, in sum, stood for Whitman as the distillation of modernity and new American social prospects. His description of both the palace and his poetics in terms of modernity, significantly, connects industrial and technological transformation to a progressive, democratizing political idealism. As had Whitman, Greeley would also characterize the Crystal Palace exhibition as genuinely modern, not simply because it captured the wonders of the industrial age but also because it revealed a social promise at midnineteenth century far superior to that of any prior historical moment:

What authorizes us to use the word progress, and to look with a complacent, halfpitying eye upon the attainments of the generations that have passed away? It is this: that in our discoveries in science, by our applications of those discoveries to practical art, by the enormous increase of mechanical power consequent upon mechanical invention, we have universalized all the beautiful and glorious results of industry and skill, [and] we have made them a common possession of the people. (Art and Industry 52) 
Arguing that mass industrial transformation in fact universalizes and "democratizes the means and appliances of a higher life" (52), Greeley asserts an underlying coherence and purpose to the increasing division of social roles and forms within industrial modernity. On this point, however, Whitman remained cautiously hopeful but never fully convinced. Although he would also assert an underlying unity to the heterogeneity of modern times, for Whitman this unity was not manifest in the material realm of commodities and production alone, but rather in the complex intersection between one's incommensurable, spiritual self and the growing diversity of the material world. Only insofar as the material bears witness to "the identities of the spiritual world" ( $L G 5)$ is material progress of any real and lasting democratic value. So while Whitman held tenuously to a rhetoric that is the functional equivalent of Greeley's, and in fact of progressive modernist discourse generally, the sheer heterogeneity and economic divisiveness of the industrial age haunted his ideals of unity, historical certainty, and, most immediately, the foundations of individual spiritual identity. And it was against this backdrop of tension between the social prospects of modernity and the social dissolution it simultaneously threatened that Whitman's most celebrated poetic negotiation of the modern age was born.

\section{III}

\section{The 1855 Leaves of Grass and the Exhibition Form}

Considered in light of the discursive context surrounding the New York exhibition, the 1855 edition of Leaves of Grass, particularly "Song of Myself," resonates with a similar but qualified stance towards the prospects of modernity. The centerpiece of Leaves of Grass, the poem that would become "Song of Myself," tropes upon a range of discursive antecedents from antebellum American culture, but the Crystal Palace exhibition served as a distinctive topos for the formal and conceptual matters most prominent in this poem. The strength of the world exhibition form, I noted above, lay in its imagined capability to capture and display the essence of world-historical development. Whitman's long and heterogenous catalogues function in similar fashion to the exhibition displays. The poem is notably "ocular-centric" in both formal presentation and in concept, with Whitman's "I" punning upon the viewing-eye at the exhibition before which the totality of historical experience and modernity is on display. Just as the exhibition metonymically represents the supposed historical culmination of time and development within the new condition of modernity, Whitman's most celebrated poem relies almost exclusively upon the trope of metonymy, rather than upon metaphor or symbol, as I demonstrate below. My objective in articulating these continuities between the Crystal Palace exhibition and Leaves of Grass, however, is not so much to argue for sources of "influence" 
upon Whitman's poetry, but rather to demonstrate that the range of similarities between the world exhibition and Leaves of Grass result from a shared discursive orientation and similar ideological frame of reference. To simply say that Whitman "borrowed" from the exhibition trope does not begin to do justice to his elaborate engagement with the implications of the spectacular modernity the exhibition had set forward.

To begin, one may note that the search for a method of enclosing the heterogeneity of modern experience was a shared goal of both the exhibition and the 1855 Leaves of Grass. The poet's goal, Whitman argues in the 1855 preface, is to become a "kosmos" himself-a shared root of "cosmopolitan" similarly intended to signify a thoroughly universal and modern perspective, one that encloses culture and nature, past and present. In the preface to the 1855 Leaves of Grass, Whitman declares this goal the singular task of the modern poet:

The American poets are to enclose old and new . . . Of them a bard is to be commensurate with a people. To him the other continents arrive as contributions. [. . .] he incarnates [the country's] geography [... . To him enter the essences of the real things and past and present events - of the enormous diversity of temperature and agriculture and mines [. . .] the free commerce [. . . the factories and mercantile life and laborsaving machinery [....] For such the expression of the American poet is to be transcendent and new. (iv, my ellipses in brackets)

Whitman's poet-kosmos is thus a type of the Crystal Palace itself. The "other continents arrive as contributions" to the poet just as the representative artifacts arrive from the nations of the world to the Crystal Palace. The diversity of articles he encloses mirror the articles at the exhibition - the products of commerce, industry, the farm, and the flora and fauna of all regions. And just as the iron and glass structure of the exhibition hall is representative of the modernity it celebrates, so also must the expression - the form - the "poet-kosmos" adopts be "transcendent and new."

When Whitman's "I" in "Song of Myself" announces himself as a "kosmos," he references a distinctly exhibition-like sense of the poet as one who "houses" modernity itself. In his 1860 poem titled "Kosmos," Whitman would define a "kosmos" as one who "includes diversity" and "is the amplitude of the earth," who, "constructing the house of himself or herself" sees "races, eras, dates, generations, / The past, the future, dwelling there, like space, inseparable together" (LG 392-393). The metaphor of a "kosmos" as a "house" enclosing the diversity of history, time and space, whether intended or not, distinctively parallels the Crystal Palace. And many of the cosmic pronouncements of the " $I$ " in "Song of Myself"- "I contain multitudes (55)," "I resist anything better than my own diversity (24)," "I am an acme of things accomplished, and an encloser of things to be" (50)-might just as easily have hung above the entrance to the Crystal Palace Exhibition. 
The cosmic identification of the poet with global experience leads directly to the unique figurative strategy common to the world exhibition and to "Song of Myself." Metonymic articulation of the interconnectedness between producers, products, regions, and disparate eras of time is the dominant trope of "Song of Myself." The poem's "transcendent and new" form of expression is, in fact, an unbroken metonymy by means of which seemingly disparate forms are shown to be contiguous elements of the totality of natural and cultural history. ${ }^{18}$ While Whitman is often credited with popularizing free-verse poetry, his most celebrated poem departs just as radically from nineteenth-century poetic convention in its virtual abandonment of metaphorical and symbolic figures. Metonymic connectivity, not metaphorical comparison or symbolic representation, best describes the figurative structure of the poem. And the subtle but distinct conceptual difference between "metaphor" and "metonymy" provides the motive for Whitman's almost exclusive reliance upon metonymic troping in the first edition of Leaves of Grass. Metaphor require separateness as a linguistic precondition, insofar as metaphorical meaning is produced in the articulation of a similarity between disparate terms. Roman Jakobson thus places metaphor and metonymy as opposite poles of the figurative spectrum, noting that metaphorical discourse operates through "selection and substitution," while metonymic discourse stresses "combination and contexture."19 Because Whitman's speaker in "Song of Myself" refuses the pre-condition of separateness among forms, forging instead a radical equivalence and bond among things, selection and substitution are systematically avoided throughout the poem. The speaker repeatedly stresses contiguous association in the poem as he rejects any discourse based upon temporal or relative difference: "I know I have the best of time and space - and that I was never measured, and never will be measured" (51); "I do not talk of the beginning and the end," (14); "I do not call one greater and one smaller" (49); "There is no stoppage, and never can be stoppage" (51).

The prevailing metonymic character of "Song of Myself" is all but consciously elaborated upon in the poem's famous lines about the meaning of "the grass." "Grass" is often identified as a guiding metaphor or symbol in the poem; F. O. Mathiessen, for instance, conventionally describes it as "the central symbol" of the poem ${ }^{20}$ (547). However a close reading of this famous section shows the speaker attempting and then failing to find a conclusive metaphorical or symbolic meaning in the grass, only an overtly metonymic one. When the child asks "What is the grass," the speaker answers in the well-known series of metaphors. However the "meaning" of each of these metaphors is notably weakened by the speaker's own equivocations:

How could I answer the child?. . . I do not know any more than he.

I guess it must be the flag of my disposition, out of hopeful green stuff woven. 
Or I guess it is the handkerchief of the Lord,

A scented gift and remembrancer designedly dropped,

Bearing the owner's name in the corners that we may see and remark, and say Whose?

Or I guess the grass is itself a child. . . . the produced babe of vegetation.

Or I guess it is a uniform hieroglyphic [ . . . ].

And now it seems to me the beautiful uncut hair of graves. (16, emphasis mine)

Whitman's marking of each metaphorical response with such uncharacteristic ambivalence is surprisingly out of character with the certain, even strident voice in other sections of the poem. And the successive string of uncertain and quaintly sentimental metaphors ("the handkerchief of the Lord") signals the reader that each guess is inadequate to the task of fully answering the child's question. Yet this initial ambivalence stands in marked contrast to the ensuing lines, where the grass is conversely identified through a stark metonymy that combines grass and the graves of the dead into a common texture that is at once representative and literal:

\section{O I perceive after all so many uttering tongues!}

And I perceive they do not come from the roofs of mouths for nothing.

I wish I could translate the hints about the dead young men and women,

And the hints about the old men and mothers, and the offspring taken soon out of

their laps.

What do you think has become of the young and old men?

And what do you think has become of the women and the children?

They are alive and well somewhere;

The smallest sprout shows there is really no death,

And if ever there was it led forward life, and does not wait at the end to arrest it, And ceased the moment life appeared. (16-17, emphasis mine)

When the speaker perceives "after all" the meaning of the grass, all preceding metaphorical speculation is consequently displaced by the grander, all-encompassing metonymy. The grass serves as a metonymy, rather than as a metaphor, because its significance ultimately derives from the total process of organic and figurative transformation, wherein people, grass, elements, even human utterance, are thoroughly integrated. There is no identifiable moment where the buried dead "end" and the grass "begins." The grass, then, does not merely "stand for" the dead in a metaphorical or symbolic comparison, but rather is itself consubstantial with them, both figuratively and literally, in the ongoing perpetuation of life.

A similar metonymy informs another reference to the grass in the poem: "I believe a leaf of grass is no less than the journeywork of the stars" (34). A "leaf of grass" and the "journeywork of the stars" do not compare on the basis of metaphorical similarity; rather the leaf of grass is understood, metonymically, as a single node of contiguity in a vast, interconnected and cosmic process that ultimately unites the blade on 
earth with the outermost material of the firmament. Metonymic contiguity, rather than metaphorical exchange or symbolic equivalence, best identifies Whitman's figurative use of the grass in the poem, as well as the radical interconnectedness his speaker forges between all things. And metonymic display similarly enables representation of the productive interrelationship of past and present, as well as culture and nature that binds the varieties of human enterprise democratically presented within the Crystal Palace.

While the conceptual attraction of a radical metonymy is apparent, given Whitman's democratic longings, a potential danger appears to have become equally apparent to Whitman. Kenneth Burke offers the term "reduction" as a substitute for "metonymy," because insofar as a particular form is understood in relation to a vast totality, it may itself be reduced to the sum of the totality. ${ }^{21}$ Moreover, if any specific form or person is but a temporary and interchangeable manifestation of the general process, then the uniqueness of identity and selfhood is threatened with imminent dissolution into a nebulous, undifferentiated whole. Whitman's "I" repeatedly pronounces that he is not "contained," but what keeps him from becoming utterly dissolved? Whitman negotiates this complication by asserting two capacities that preserve individual specificity and uniqueness: speech and vision. ${ }^{22}$ The speaking "I" of "Song of Myself" puns on his dual association with speech and vision throughout the poem. The poet at one point declares that "speech is the twin of my vision" and that speech is "unequal to measure itself" (31). For Whitman, the significance of these associations rests in an imagined incommensurableness of speech and the eyesight. The capacities to look and to talk serve as the irreducible locus of individual identity within an otherwise reductive totality, yet as I demonstrate below, Whitman's uncertainties about the spectacular and increasingly mediated visual experience of modernity pushes Whitman to qualify his terms to the point of near incomprehensibility.

When Dostoevsky's Underground Man faced the London Crystal Palace, as I noted in the previous section, he believed himself dissolved and rendered insignificant by its culminating claim to temporal perfection. Whitman, however, indirectly questions the power of the spectacular Crystal Palace to undermine his individuality because the very gaze of an individual is for him the locus of a certain irreducibility of the self. The preface thus asserts:

what the eyesight does to the rest [of humanity] he [the poet] does to the rest. Who knows the mystery of the eyesight? The other senses corroborate themselves, but this is removed from any proof but its own and foreruns the identities of the spiritual world. (v)

This "removal" of the eyesight "from any proof but its own" gives it an oddly intermediate power to negotiate the tension between specificity 
and totality. Eyesight "foreruns" the identity of the spiritual world, yet significantly, is not equivalent to that world, either. In associating the eye with the identity of the "I," Whitman mediates between both a material and spiritual reduction of identity, the implicit danger of the encompassing metonymy the poet otherwise celebrates. "Seeing" functions as a kind of middle ground, ${ }^{23}$ unique to the capacity of an individual; even though the objects of one's perception may be encompassed within the metonymic whole, these are themselves encompassed by the gaze of an individual. So while Underground Man does not feel he can even stealthily stick out his tongue at the Crystal Palace, Whitman's "I" can declare, in a phrase that seems all but directed at the New York Crystal Palace: "Encompass worlds but never try to encompass me, / I crowd your noisiest talk by looking toward you" (31, emphasis mine). ${ }^{24}$

Speech, for Whitman, is similarly unequal to measure: "My voice goes after what my eyes cannot reach, / With the twirl of my tongue I encompass worlds and volumes of worlds" (31). Whitman underscores the significance of speech in his metonymy of the grass, in which the meaning of the grass is revealed as the "I" perceives "so many uttering tongues." Thus through the indissoluble power of utterance the dead appear in the poet's revery to attain an identity somewhat independent of sheerly organic processes of decomposition and reconstitution, as in the case of the eyesight. However between speech and the eyesight, the eyesight remains the primary grounding of identity throughout the poem, superseding "the noisiest talk," and ultimately becoming inscrutable to language itself, as the poet declares: "Writing and talk do not prove me, / I carry the plenum of proof and everything else in my face" (31). Although speech is the "twin" of vision, vision is not itself reducible to speech. In the most essential sense of the term, "identity" for Whitman emanates from each individual's capacity to see.

In addressing the conflict between unique selfhood and commonality, Whitman distinguishes between that part of him which is metonymically incorporated in the whole and the part of him which is a uniquely seeing "I." In one of the poem's odd sub-divisions of the speaker's identity, the metonymic "me" is thus distinguished from the watching "Me myself":

Trippers and askers surround me,

People I meet . . . . the effect upon me of my early life . . . of the ward and city I live in .... of the nation,

The latest news .... discoveries, inventions, societies . . . . authors old and new,

My dinner, dress, associates, looks, business, compliments, dues,

The real or fancied indifference of some man or woman I love,

The sickness of one of my folks - or myself . . . or ill-doing . . . or loss or lack of money .... or depressions or exaltations,

They come to me days and nights and go from me again,

But they are not the Me myself. (15) 
In contrast to a quotidian, metonymically determined identity - the "me" of daily life - the speaker's incommensurable and predominantly ocular "Me myself" is elaborated in the next stanza:

Apart from the pulling and hauling stands what I am,

Stands amused, complacent, compassionating, idle, unitary,

Looks down, is erect, bends an arm on an impalpable certain rest,

Looks with its sidecurved head curious what will come next,

Both in and out of the game, and watching and wondering at it. (15, emphasis mine)

The "Me myself" here looks and watches, presumably gaining his "unitary," as opposed to merely quotidian, identity through this capacity to stand apart and watch, to even watch himself watching. Although Whitman's reflective "Me myself" here somewhat resembles the transcendent subject in Romanticism, the surrounding verbs suggest little of the contemplative solitude of the romantic, but rather direct engagement with the modern world. Thus while the "Me myself" is apart from the "pulling and hauling," he is still intermediately connected-"both in and out of the game." Eyesight enables this capacity of being both in and out of the game because while seeing foreruns the identity of the spiritual world it is also materially embedded, yet not to the point of inevitable dissolution and recombination, as is the case with the other half of the self, the metonymic "me" in the world. Thus because it is neither fully transcendent nor utterly base, vision enables the unique halfway ground upon which the "what I am" of Whitman's speaker ultimately stands.

Insofar as the bounds which form the incommensurable identity of the "I" are located somewhere within the mystery of the eyesight, however, an additional problem emerges for Whitman. Identified by vision, the " $\mathrm{I}$ " is endangered by a potentially superficial world of empty representation and mere spectacle. And it is here that the spectacular modernity of the Crystal Palace and its contents appear to undermine the speaker's earlier dismissal. Whitman's attempt to negotiate the danger of self-dissolution by dividing identity between the metonymic "me" and the ocular "me myself" does not preclude an equally damaging reduction from the other side; if the metonymy Whitman posits throughout "Song of Myself" threatens to reduce a particular individual to the point of dissipation into the totality, identification with the visual alone may similarly threaten to reduce one's being in the world to the terms of a spectacle show, distorting the supposed cosmic significance of an individual. Whitman's final panoramic catalogue in the poem is telling in this regard. After concluding with the speaker's familiar claim of cosmic enclosure ("I rise extatic through all, and sweep with true gravitation, / The whirling and whirling is elemental within me") a sudden reversal occurs that opens the possibility of visual reduction and mistaken perception: 


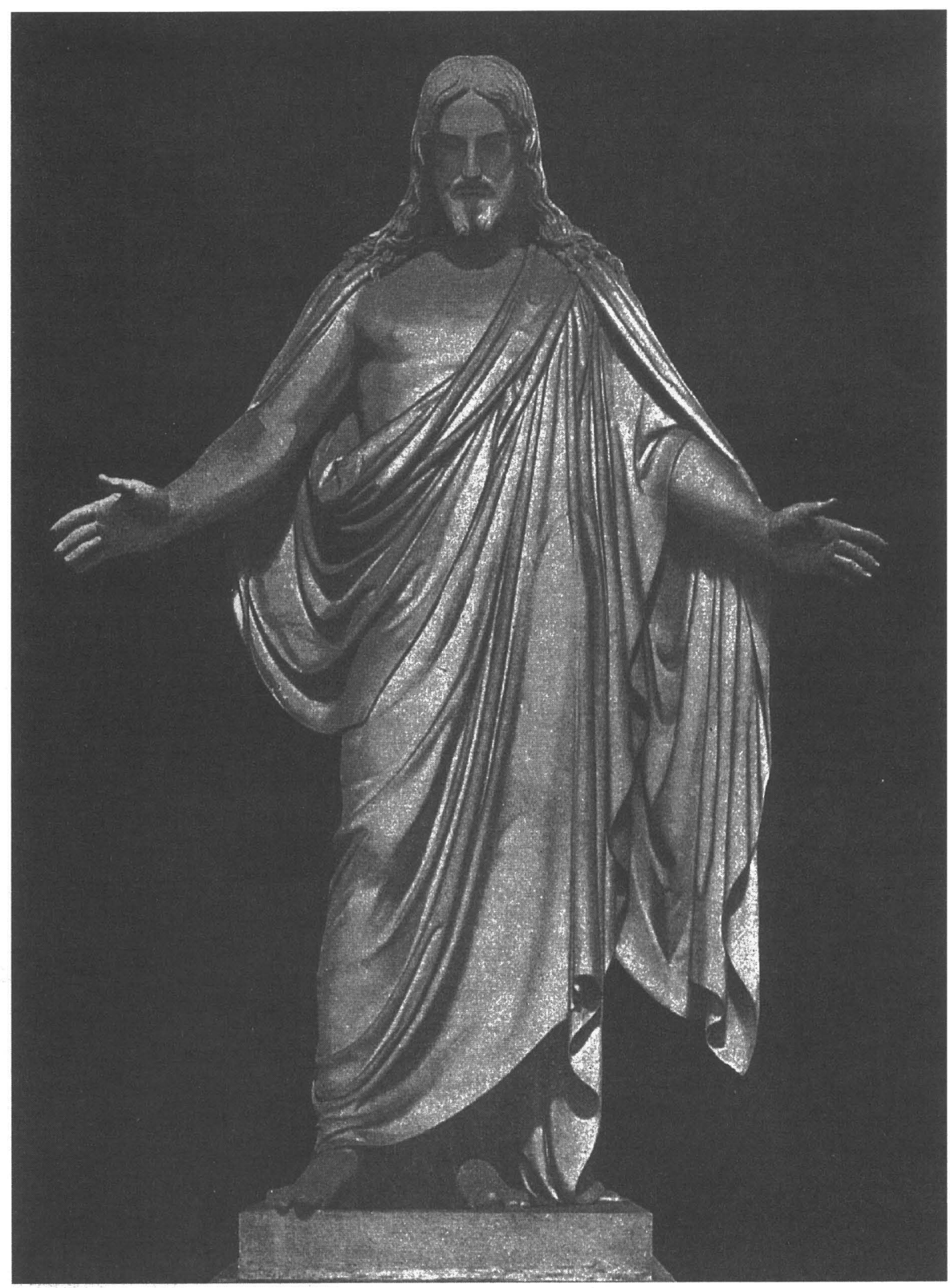

Figure 3. Bertel Thorwaldsen's "Christ." From Thorwaldsen: Kunstler-Monographien 16, Leipzig: 1896. 
Somehow I have been stunned. Stand back!

Give me a little time beyond my cuffed head and slumbers and dreams and gaping, I discover myself on a verge of the usual mistake.

That I could forget the trickling tears and the blows of the bludgeons and hammers!

That I could look with a separate look on my own crucifixion and bloody crowning!

Mark Bauerlein reads the peculiar "messianic identification" in this passage as Whitman's ultimate acting out of the "fantasy [of] co-experiencing" which repeats throughout the poem. ${ }^{25}$ The speaker's abrupt recognition of the limits of "co-experiencing," however, appears more directly at issue. The "separate look" upon Christ, even as the "I" identifies himself with Christ, has estranged the speaker from vital experience and necessary knowledge of Christ's suffering. Coming on the heels of another panoramic catalogue, the "usual mistake" of the otherwise strident speaker is his failure, for all of his spectacular presentations and enumerations, to be fully unified and sympathetic with the objects he contemplates. He appears to admit a regular failure, in other words, to properly align his own cosmic gaze with the vital meaning of the objects. The speaker appears to have identified with Christ through the same process of visual identification which binds the "I" to all it perceives. But in doing so he is suddenly "stunned" into an awareness of his ultimate otherness, of his looking with a "separate look" not commensurate to the experience of Christ's suffering. This is a crucial moment in the poem, because it is a rare moment where the otherwise cocksure singer is haunted by the specter of alienation. That his "slumbers," "dreams," and especially his "gaping" have led him to the brink of self-deception is suggestive, as each term introduces the very possibility of falseness and alienating distance which the speaker has repeatedly denied throughout the poem.

The odd allusion to Christ in this section is quite possibly connected to the 1853 exhibition as well. If Holloway's anecdote can be believed, Whitman was transfixed by Thorwaldsen's massive nordic Christ showing his wounds to the Twelve Apostles. Whitman's memoranda on the exhibit also recalls Thorvaldsen's "colossal" figures, which Greeley reported were "the great attraction among the sculptures of the Palace," and "the most generally admired feature of the Exhibition" (Art and Industry 61-62). The towering Christ is not directly evoked in Whitman's lines describing the "crucifixion and bloody crowning," but this omission may well serve the point. One may too easily "gape" with a "separate look" at the spectacular image of Christ, estranged as an iconic spectacle from the real suffering and misery of the historical Jesus in Jerusalem, an identification Thorwaldsen's triumphant Christ all but precludes (see Figure 3). "The mockers and insults," along with "the trickling tears and the blows of the bludgeons and hammers" are erased before the gaping eye and falsely separate look of the exhibition goer. 
And if the oblique reference in "Song of Myself" is not alluding to Thorwaldsen's christus at the Crystal Palace, the emphasis on the danger of the "separate look" almost certainly references the danger of "gaping" - seeing without knowing - at any spectacular icon or image. If one encounters the spectacular without a genuine wholeness of vision, the speaker suggests, one may falsely mistake mere semblance for true substance.

Whitman's wavering on this point-his admission that the fulness and the reality of an object are open to loss and distortion in relationship with a viewer - threatens to unravel the broadest claims of the poem. The eyesight might serve as an irreducible locus of identity in a world of metonymic blending, but the Christ-passage indicates that "meaning" for Whitman ultimately requires an "extra-visual" foundation as well. And this problem is not merely semantic; the exhibition may offer up a spectacular world for the gaze, but a world whose significance and promise may not be "properly" seen. This alienating danger is underscored by Whitman's notion of a "separate look," suggesting as it does a distorted relationship between eyesight and empathy. Consequently, Whitman's foundation for identity, eyesight, is itself divided in the poem, just as the "I" earlier split into the "me" and the "me myself." The difference between a "look" and a "separate look" is akin to the difference between "seeing" and "gaping"; the former signifies genuine understanding and cosmic perspective, while the latter is characterized as mistaken, forgetful and dreamlike - a difference comparable to one's attaining requisite enlightenment at the exhibition versus merely becoming enchanted by it.

Despite the sweeping democratic claims of the poem, anxiety over how one negotiates the spectacles of modernity ultimately leaves Whitman rather didactically instructing his readers as to how they should properly see their world. Promising to rid his audience of "contemptible dreams" and to "wash the gum" from its eyes, he declares: "Do you not see $\mathrm{O}$ my brothers and sisters? / It is not chaos or death . . . it is form and union and plan. . . it is eternal life. . . it is happiness" $(52,55)$. Such underlying truths are apparently not self-evident, at least not to all eyes. Whitman's speaker thus feels compelled to assert, on the reader's behalf, the dwindling "reality" behind all the spectacular visual mediations of modernity:

The panorama of the sea . . . but the sea itself?

The well-taken photographs . . . . but your wife or friend close and solid in your arms?

The fleet of ships of the line and all the modern improvements . . . but the craft and pluck of the admiral? (48)

In the instance of the panorama and the photograph, the representation of the thing alone is insufficient; it should, as Whitman reminds the 
reader, "indicate reality," but not substitute for the realities of touch, being-with, or the thing itself. The potential for alienation Whitman identifies in these simulacra does not make them intrinsically "dangerous" forms. But the viewer must learn to see the more substantial "reality" they indicate. "All the modern improvements" must likewise not eclipse the less spectacular qualities of the laborer's skill and the humanity which produce these technologies. A conspicuous anxiety lurks behind Whitman's "corrections" in lines such as these, a fear that may well extend to the spectacular experience of modernity as displayed at the New York exhibition (where these very objects were displayed and celebrated). Whitman, significantly, does not discount the promise of the modern age here, but certainly betrays a fear that the social prospects of modernity may be overtaken by its material productions.

Whitman's felt need to sustain an incommensurable site of identity and a visionary social perspective in the face of modern spectacle continues in the poem directly following "Song of Myself" in the 1855 edition which would later become "A Song for Occupations." Much of the catalogue-like content of this poem directly connects to the displays at the Crystal Palace exhibition ${ }^{26}$ - and although I have focused my analysis primarily upon "Song of Myself" because I believe it to be Whitman's most elaborate exchange with the modernity of the exhibition form, other of the 1855 poems make use of similar figures and engage similar concerns. Even more pointedly than "Song of Myself," the speaker in "Occupations" cautions that the array of modern objects and new forms must not substitute for the incommensurate identity of an individual: "In them not yourself . . . . you and your soul enclose all things, regardless of estimation" (63). Whitman's speaker goes on to declare that not until "the minted gold in the vault smiles like the nightwatchman's daughter," or "warrantee deeds loafe in chairs opposite and are my friendly companions," will he "make as much of them as I do of men and women" (64). That people must be reaffirmed against gold and warrantee deeds, however, is itself a notable retreat from the passive and confident opening claim in "Song of Myself," that "to elaborate is of no avail" (14) for the "I" who brings "no mockings or arguments" (15). That such ambivalent undertones in "Song of Myself" and "Song for Occupations" connected to the forms of modern spectacle that the exhibition set on display is telling; these demurs foreshadow an anxiety that would grow with Whitman, who in later years struggled to salvage his vision of the nascent promise of industrial modernity he witnessed at the Crystal Palace against what he perceived as a self-destroying spectacle of materialism that, ironically, had its origins there as well.

Fear of the social consequences of industrial modernity grew with Whitman from the 1850 s onward, to the point that the memoirs he compiled in the late 1880 s largely distance him from the hopeful met- 
onymic vision at the center of "Song of Myself." Although he celebrated subsequent exhibitions both at home and abroad, Whitman came to view his initial enthusiasm for modernity as naive and even misguided. His late admission of misgiving toward the project of celebrating modernity in Leaves of Grass is a telling reversal of sentiment:

Modern science and democracy seem'd [in the 1850s] to be throwing out their challenge to poetry to put them in its statements in contradistinction to the songs and myths of the past. As I see it now (perhaps too late,) I have unwittingly taken up that challenge and made an attempt at such statements-which I would certainly not assume to do now, knowing more clearly what it means. (658)

Whitman's aesthetic evolution in the later period of his poetry followed this course of increasing skepticism toward the prospects of industrial modernity. Sensing in the later nineteenth century the reduction of technology, labor and production to capitalist motives, instead of the liberal social transformation he had earlier envisioned, must have appeared to Whitman the fruition of the latent fears that mark the ambivalence of the first edition of Leaves of Grass. Later poems that took up the question of modernity most directly, such as the spiritually charged, mythic re-articulation of the historical present from the standpoint of a redemptive past in the 1871 "Passage to India," are notably more passive and circumspect in their tone. Such renegotiations of the prospects of modernity make sense in light of the fears that show themselves as early as 1855; without a firm grounding for social promise and spiritual identity, modern industry might reduce all social promise to sheerly material motives, obliterating cosmic purposes for both nation and individual.

As the progressive metonymy of the Crystal Palace exhibition and Whitman's analogous (if demurring) vision in the 1855 Leaves of Grass make clear, modernity at mid-nineteenth century already showed itself striking a precarious balance between social promise and alienating material spectacle. Whitman's encounter with both the promise and danger of the world exhibition form furthered not only his celebrated innovations in poetic form, but also his pursuit of an incommensurable site of self-identification within an age of spectacular cultural transformation. And if Whitman's project failed to alter the social outcomes of industrial modernity and its cultural reception in the United States, his poetic motives certainly remain as compelling within the condition of modernity today as they were in Walt Whitman's own modern times.

\section{Brigham Young University}




\section{NOTES}

1 Leaves of Grass: A Comprehensive Reader's Edition, edited by Harold W. Blodgett and Sculley Bradley (1965), 198. Future citations, except where otherwise indicated, will be to this edition and cited in text as $L G$.

2 Whitman: An Interpretation in Narrative (New York: Alfred A. Knopf, 1926), 97.

3 David Reynolds offers a brief critical discussion of Whitman's relation to the event, connecting it to a larger American "exhibition culture" in Walt Whitman's America: $A$ Cultural Biography (New York: Alfred A. Knopf, 1995), 301-303. Ezra Greenspan touches upon "visceral" analogies between the 1853 exhibition and "parts of several of [Whitman's] 1855 poems" in Walt Whitman and the American Reader (Cambridge: Cambridge University Press, 1990), 7-8. Miles Orvell cites the exhibition gallery of the Crystal Palace as one of the "omnibus forms" after which Whitman patterned the heterogeneous displays of his early poems. See The Real Thing: Imitation and Authenticity in American Culture, 1880-1940 (Chapel Hill: University of North Carolina Press, 1989), 3-29.

4 See Charles Harvard Gibbs-Smith, The Great Exhibition of 1851 (London: H.M.S.O., 1981), 15-19.

5 The Dialectics of Seeing: Walter Benjamin and the Arcades Project (Cambridge: The MIT Press, 1991), 85.

6 See Art and Industry as Represented at the Exhibition at the Crystal Palace, New York, 1853-54 (New York: 1854), 14-15. Greeley served as both editor and primary author of this text, the most comprehensive account of both the history and the various exhibits displayed at the Crystal Palace. As a shareholder, Greeley had a vested interest in portraying the exhibition in most ideal terms, as citations from this text which follow will make clear. Even so, the writings of Greeley's contemporaries (Whitman's in particular) indicate that Art and Industry is an accurate barometer of the prevailing discourse surrounding the event of the exhibition. Future references will be cited in text.

7 This image of the London Crystal Palace (courtesy of Brigham Young University Special Collections, publisher unknown) nicely illustrates the metonymic and "cosmoramic" character of the world exhibition. The inset palace "contains" the various regions and times of global experience, thus becoming not so much a particular place, but the embodiment of the historical culmination that marks the temporal present-modernity-itself.

8 Reflections: Essays, Aphorisms, Autobiographical Writings, translated by Edmund Jephcott, edited by Peter Demetz (New York: Harcourt, Brace, Jovanovich, 1978), 152-153.

9 Fust Looking: Consumer Culture in Dreiser, Gissing and Zola (New York: Methuen, 1985), 2.

10 Quoted in Justin Kaplan, Walt Whitman: A Life (New York: Simon and Schuster, 1980), 179.

11 Fyodor Dostoevsky, Notes from Underground, translated by Mirra Ginsburg (New York: Bantam Books, 1992), 27.

12 All That Is Solid Melts Into Air: The Experience of Modernity (New York: Penguin Books, 1988), 236. 
13 Here and throughout the essay I cite page numbers from the original 1855 edition of Leaves of Grass, unless otherwise noted, in order to maintain clarity in the face of Whitman's later revisions. A facsimile of the 1855 edition, published by Eakins Press (New York, 1966), is an available corroborating reference source for the text and pagination of the first edition.

14 Cleveland Rogers and John Black, eds., The Gathering of Forces (New York: Putnam's, 1920), 365. Further citations will be in text.

15 Quoted in Greenspan, 238.

16 The editorial appeared in the July 29, 1853, issue of the Tribune.

17 Emory Holloway and Vernolian Schwarz, eds., I Sit and Look Out: Editorials from the Brooklyn Daily Times by Walt Whitman (New York: Columbia University Press, 1932), 129-130.

18 C. Carroll Hollis's Language and Style in Leaves of Grass (Baton Rouge: Louisiana State University Press, 1983) offers an extended analysis of the lexical and figurative dimension of Whitman's poetics. Hollis rightly notes in his chapter on "metonymy" that "metaphors in Leaves are notable chiefly for their rarity" (202). His analysis, however, remains largely formal, documenting rather than explaining the distinctive predominance of this trope in Whitman's verse. In the brief analysis which follows I connect Whitman's metonymic vision, at least in part, to his encounter with the predominantly metonymic form of representation the modern world exhibition offered.

19 Jakobson stresses that both aspects are necessary to language, but that different discursive forms, especially literary forms, might be characterized as predominantly metaphorical or metonymical. He notes that "the primacy of the metaphoric process in the literary schools of romanticism and symbolism has been repeatedly acknowledged," but that the "predominance of metonymy . . . underlies and actually predetermines the so-called 'realistic' trend, which belongs to an intermediary stage between the decline of romanticism and the rise of symbolism" (23). Although Jakobson is referring here to the realistic novel's metonymic tendency to "follow the path of contiguous relationships," dissolving plot into atmosphere and characters into their setting in space and time, the suggestion of an "intermediary stage" where literary style is predominantly metonymic corresponds to Whitman's early poetry, which incorporates the implicit metonymy in the universalist discourses and forms of the midnineteenth century, like the "world exhibition." See "The Metaphoric and Metonymic Poles," Contemporary Critical Theory, ed. Dan Latimer (San Diego: Harcourt Brace Jovanovich, 1989) 22-27.

20 See American Renaissance: Art and Expression in the Age of Emerson and Whitman (New York: Oxford University Press, 1947), 547.

21 See A Grammar of Motives (Berkeley: University of California Press, 1969), 507.

22 Recent scholarship on the visual element in Whitman's poetry and poetics comprises an important sub-field in Whitman studies. While this essay attends mainly to the conceptual implications of vision and identity within "Song of Myself," it resonates with the issues of other critical work on the visual in Whitman. See especially Ed Folsom's discussion of Whitman's response to photography in Walt Whitman's Native Representations (Cambridge: Cambridge University Press, 1994) 99-126; James Dougherty's look at visual representation and Whitman's poetics in Walt Whitman and the Citizen's Eye (Baton Rogue: Louisiana State University Press, 1993) 172-201; and Graham Clarke's The Poem as Private History (New York: St. Martin's Press, 1991), 127-153. 
23 Throughout "Song of Myself," this irreducible middle space between spiritual and material is upheld. When the "I" addresses his soul, for instance, he's careful maintain this space: "I believe in you my soul . . . . the other I am must not abase itself to you, / And you must not be abased to the other" (15). Carolyn Porter locates a similar middle ground in Emerson's conception of "spirit," which serves as "ontological referent not for sign or for signified, but for the act of signification itself." Emerson's "transparent eyeball" is perhaps the analogue to Whitman's sense of "seeing"as incommensurable and self-referential. See Seeing and Being: The Plight of the Participant Observer in Emerson, Fames, Adams, and Faulkner (Middletown, Connecticut: Wesleyan University Press, 1981), 103-105.

24 In later editions of Leaves of Grass, Whitman's revision of this line even more readily invokes the specular image of modern achievement such as the world exhibition offered: "Encompass worlds, but never try to encompass me, / I crowd your sleekest and best by simply looking toward you" ( $L G 55$, revision italicized). The new terms "sleekest and best" suggest the ultra-modern Crystal Palace, encompassing worlds but nonetheless contained by a simple look.

25 See Whitman and the American Idiom (Baton Rouge: Louisiana State University Press, 1991), 43.

26 Virtually every item listed in the "catalogue" of "A Song for Occupations" was a display item at the 1853 exhibit. The comparison would be too lengthy for this essay, but the New York Daily Tribune for January 20, 1854, lists the awards presented for each category, in agriculture, woodworking, confectionery, photography, printing, and in several other categories which directly correspond to implements listed in the poem. 